\title{
Accidental discovery of the left ventricular diverticulum
}

\author{
Margarita Brida*, Irena Ivanac Vranešić, Vice Nakić, Jadranka Šeparović-Hanževački, \\ Anton Šmalcelj, Eduard Margetić, Petra Angebrandt \\ University Hospital Center Zagreb, Zagreb, Croatia
}

Congenital diverticulum of the left ventricle is a very rare cardiac anomaly due to local embryological developmental failure. We present a case of a 22-year old male patient. He is a former athlete who as a part of preoperative examination for the planned right knee surgery made an ECG which showed signs of left ventricular hypertrophy. Two-dimensional transthoracic echocardiography revealed rare congenital heart disorder in the form of large left ventricular apical diverticulum. Diverticulum measured $5.2 \times 2.4 \mathrm{~cm}$ and occupied left ventricular apex with an entrance width of $2.3 \mathrm{~cm}$. Diverticulum exhibited good wall contractility with three layer structure, accentuated trabeculations as well as aberrant cords imitating third AV valve at the diverticular entry. Overall, diverticulum appeared much alike small third ventricle. The patient had normal coronary angiography findings, negative family history of sudden cardiac death and normal 24hour Holter ECG - sinus rhythm without arrhythmias. Ta- king into account these points, mainly the absence of associated other cardiac abnormalities and since the patient was asymptomatic we decided to follow up the patient without surgical treatment.

KEYWORDS: left ventricular diverticulum, echocardiography, congenital heart disease.

\section{Received: $20^{\text {th }}$ Mar 2013}

*Address for correspondence: Klinički bolnički centar Zagreb, Kišpatićeva 12, HR10000 Zagreb, Croatia

Phone: +385-1-2388-888

E-mail: maggybrida@yahoo.com

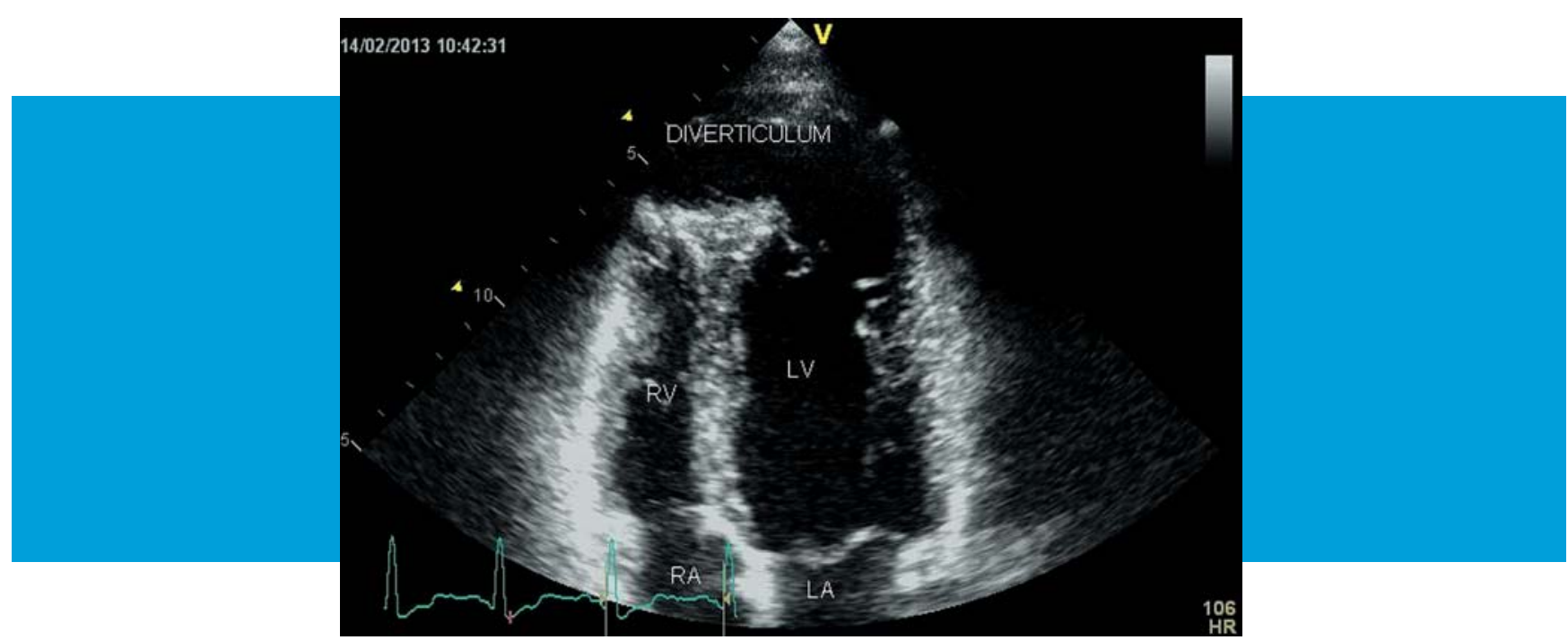

Figure 1. The four chamber view presenting left ventricle apical diverticulum.

\section{Literature}

1. Bilgin M, Yildiz S, Gul I, Nalbantgil S. Isolated congenital left ventricular diverticulum in an adult. Echocardiography. 2013;30(3):E78-80

2. Bayrak F, Guneysu T, Degertekin M, Gemici G. Isolated left ventricular diverticulum in an asymptomatic patient. Eur Heart J. 2007;28(13):1591.

3. Vaidiyanathan D, Prabhakar D, Selvam K, Alagesan R, Thirunavukarasu N, Muthukumar D. Isolated congenital left ventricular diverticulum in adults. Indian Heart J. 2001;53(2):211-3. 